\title{
Norms of semantic encoding variability for fifty homographs*
}

\author{
MARY FULCHER GEIS and EUGENE WINOGRAD \\ Emory University, Atlanta, Georgia 30322
}

\begin{abstract}
Ss gave word associations to the same set of 50 homographs on two occasions that were separated by either $5 \mathrm{~min}$ or $48 \mathrm{~h}$. For each homograph, the probability of S's giving, at both tests, word associations that represented the same semantic sense was determined by semantic scoring of the responses. Conditional probabilities of encoding switches also were obtained. Values are presented for each homograph. The relationship between the strength of a homograph's primary semantic sense and different test-retest encoding patterns is discussed.
\end{abstract}

Much contemporary research and theoretical activity is centered on the question of what is encoded when an item is presented for study or test in a learning-memory experiment. However, as encoding variability theory admonishes, what is stored in memory may not be the same on each occasion in which a nominally identical stimulus is presented (Martin, 1968). When the research concern has been with the semantic features of the encoded internal representation of a word event, homographs have been used frequently as the stimulus materials (e.g., Light \& Carter-Sobell, 1970; Rowe, 1973; Winograd \& Conn, 1971). A homograph is a word that has two or more semantically distinct meanings. Examples of such polysemous words are SUIT, which may refer to legal action or to wearing apparel, and YARD, which may refer to a unit of measurement or to a tract of ground.

If S's word association to a homograph is assumed to reflect the semantic properties that were encoded about that homograph, the likelihood of S's making a specific semantic encoding of a particular homograph may be inferred from semantic scoring of the traditional type of word association test (Cramer, 1970; Kausler \& Kollasch, 1970; Perfetti, Lindsey, \& Garson, 1971). With semantic scoring, judges classify each response according to the semantic sense which they believe that it represents. To illustrate, word associations of "game," "chips," and "bet" to the homograph POKER would be classified under the semantic sense of POKER as a card game, while associations of "fire," "stick," and "iron" would be classified under the semantic sense of POKER as a metal rod. For any homograph, the proportion of Ss' responses that are classified under each of its semantic senses may be considered the semantic encoding probability of that sense.

Direct data concerning the stability of a particular semantic encoding of a homograph are not provided by

*This research was supported by National Science Foundation Grant GB-18703 to the second author. The first author was supported by an NDEA Title IV fellowship from the Office or Education, HEW. Reprint requests should be sent to Eugene Winograd, Department of Psychology, Atlanta, Georgia 30322. existing norms. That is, if S encodes POKER as "card game" at Time A, what is the likelihood that he will make the same encoding of POKER at Time B? Such norms of encoding stability or variability require that a word association test be administered to the same $S$ on more than one occasion. In the present research, Ss gave word associations to the same set of homographs on two occasions that were separated by either $5 \mathrm{~min}$ or $48 \mathrm{~h}$. For each homograph, the likelihood of S's giving, at both tests, word associations that represented the same sense was determined by semantic scoring of the responses. Although some general characteristics of these norms have been reported elsewhere (Winograd \& Geis, 1974), the data for individual word encoding patterns may be useful to other investigators and are presented here.

\section{METHOD}

Since a complete description of the materials and procedure appear in Experiment II of Winograd and Geis (1974), only a summary is provided.

\begin{abstract}
Materials
Selection criteria for the 50 homographs tested are presented in Winograd and Geis. In brief, half of the words were selected because existing norms indicated that there were two likely senses, i.e., probabilities of both the primary (S1) and secondary (S2) semantic encodings were above .4, while the other 25 homographs were included because one sense was clearly dominant, i.e., $\mathrm{p}(\mathrm{S} 1)$ was greater than .8. In the test booklets, one homograph was printed on each page with a space after it for S's response. Each booklet also contained 15 nonhomograph filler items that were different for the test and retest booklets. Four random orders of the words were used.
\end{abstract}

\section{Procedure}

Small groups of Ss were tested. At each testing, $\mathrm{S}$ was given a booklet and was instructed to write down the first word that come to mind upon seeing a stimulus word. After completion of the first test booklet, Ss performed a 5-min filler task of number progression problems. In the 5-min condition, the second word association test was administered immediately after the filler task. In the 48-h condition, Ss were dismissed after the filler task and retested $48 \mathrm{~h}$ later. 
Table 1

Semantic Encoding Norms

\begin{tabular}{|c|c|c|c|c|c|c|c|}
\hline & & & & & $\mathrm{p}$ (Same) & $\mathrm{p}(\mathrm{S} 1 / \mathrm{S} 2)$ & $\mathrm{p}(\mathrm{S} 2 / \mathrm{S} 1)$ \\
\hline ADMIT & Acknowledge & .60 & Let In & .31 & .80 & .20 & .20 \\
\hline ARTICLE & Written Piece & .51 & Item & .46 & .77 & .20 & .11 \\
\hline BANK & Financial Establishment & .99 & Water's Edge & .01 & .97 & 1.00 & .02 \\
\hline BAT & Club & .68 & Mammal & .31 & .76 & .37 & .18 \\
\hline BEAM & Ray of Light & .71 & Timber & .25 & .88 & .18 & .11 \\
\hline BIT & Piece & .66 & Bridle & .21 & .78 & 16 & .43 \\
\hline BOIL & Bubble & .93 & Sore & .06 & .95 & .33 & .03 \\
\hline BOWL & Container & .54 & Game & .43 & .72 & .28 & .29 \\
\hline CABINET & Furniture & .90 & Council & .09 & .82 & .33 & .17 \\
\hline CAPITAL & Major & .85 & Assets & .12 & .86 & .50 & .09 \\
\hline CHARGE & Price & .69 & Attack & .19 & .84 & .42 & .06 \\
\hline CLUB & Organization & .54 & Stick & .29 & .72 & .32 & .25 \\
\hline COUNT & Enumerate & .81 & Nobleman & .15 & .78 & .50 & .16 \\
\hline DEED & Action & .59 & Legal Document & .35 & .80 & .18 & .22 \\
\hline DUCK & Bird & .88 & Dodge & .10 & .89 & .57 & .05 \\
\hline EXPRESS & Rapid Transport & .62 & Indicate & .37 & .81 & .05 & .42 \\
\hline FANCY & Elegant & .81 & Imagine & .12 & .90 & .25 & .08 \\
\hline FENCE & Enclosure & .87 & Sport & .09 & .90 & .50 & .03 \\
\hline GRAVE & Burial Place & .78 & Very Serious & .16 & .79 & .73 & .10 \\
\hline HIDE & Conceal & .88 & Skin & .10 & .92 & .80 & .02 \\
\hline HOST & Entertain Guests & .94 & Eucharist & .03 & .95 & .00 & .00 \\
\hline IRON & Metal & .50 & Pressing Tool & .49 & .79 & .18 & .24 \\
\hline LETTER & Communication & .88 & Alphabet Unit & .07 & .91 & .40 & .07 \\
\hline LIMP & Lame Walk & .50 & Not Stiff & .44 & .82 & .23 & .13 \\
\hline MAD & Angry & .53 & Insane & .44 & .77 & .23 & .23 \\
\hline MEAL & Food & .96 & Grain & .04 & .92 & .67 & .05 \\
\hline MUG & Container & .81 & Assault & .12 & .80 & .09 & .75 \\
\hline ORGAN & Musical Instrument & .87 & Body Part & .10 & .83 & .57 & .12 \\
\hline PARK & Recreation Area & .60 & Leave & .40 & .81 & .15 & .26 \\
\hline PEN & Writing Tool & .96 & Enclosure & .01 & .97 & .00 & .03 \\
\hline PITCHER & Container & .50 & Baseball Player & .49 & .67 & .26 & .39 \\
\hline POKER & Card Game & .91 & Metal Rod & .09 & .91 & .67 & .03 \\
\hline POT & Container & .72 & Marijuana & .22 & .89 & .11 & .13 \\
\hline RASH & Skin Eruption & .69 & Hasty & .26 & .78 & .28 & .19 \\
\hline RIGHT & Correct & .81 & Direction & .18 & .88 & .42 & .06 \\
\hline RING & Circular Object & .65 & Sound & .32 & .78 & .48 & .09 \\
\hline SAGE & Wise Man & .56 & Plant & .37 & .82 & .10 & .28 \\
\hline SEAL & Close & .38 & Mammal & .29 & .56 & .42 & .29 \\
\hline SEASON & Time of Year & .94 & Flavoring & .04 & .96 & 1.00 & .00 \\
\hline SECOND & Ordinal Number & .50 & Unit of Time & .50 & .79 & .21 & .21 \\
\hline SENTENCE & Grammatical Unit & .81 & Penalty & .15 & .88 & .60 & .04 \\
\hline SHIFT & Change & .76 & Time Period & .13 & .89 & .67 & .00 \\
\hline SOLE & Bottom of Foot & .71 & Only & .15 & .78 & .20 & .09 \\
\hline STABLE & Barn & .62 & Unchanging & .34 & .80 & .35 & .12 \\
\hline STERN & Severe & .84 & Ship's Rear & .15 & .86 & .33 & .10 \\
\hline STRAND & Piece & .84 & Leave Behind & .07 & .89 & .33 & .02 \\
\hline TIP & Gratuity & .59 & Edge & .35 & .65 & .39 & .28 \\
\hline TOLL & Fee & .93 & Quantity Affected & .03 & .95 & .00 & .00 \\
\hline VOLUME & Space & .47 & Book & .41 & .79 & .04 & .00 \\
\hline WATCH & Timepiece & .65 & Observe & .32 & .69 & .50 & .20 \\
\hline
\end{tabular}

\section{Subjects}

Emory undergraduates participated to fulfill a course requirement. There were $38 \mathrm{Ss}$ in the $5-\mathrm{m}$ in condition and $30 \mathrm{Ss}$ in the 48-h condition.

\section{Scoring}

Two judges independently classified the associations according to the semantic sense that each represented. A third judge resolved the scoring disagreements (only $5 \%$ of all responses). Six percent of the associations could not be subsumed under a reasonable semantic sense and were excluded from the results.

\section{RESULTS AND DISCUSSION}

The results for each homograph are shown in Table 1. in the three columns of Table 1 . The entries are for
Beside each word, the definition of its primary semantic sense (S1) is given, and the encoding probability of S1, i.e., the likelihood of S's giving at first test an association that represented $\mathrm{S} 1$, appears in parentheses. The definition of the secondary semantic sense (S2) and its encoding probability are listed next. The encoding probabilities of S1 and S2 were based on the data from the first tests for $\mathrm{Ss}$ in both conditions $(\mathrm{N}=68)$. Probabilities for tertiary senses are omitted because of the small number of associations (3\%) that were classified under S3.

Norms of semantic encoding variability are presented 
Table 2

Correlations Between Normative Strength of Primary Encoding and Test-Retest Patterns

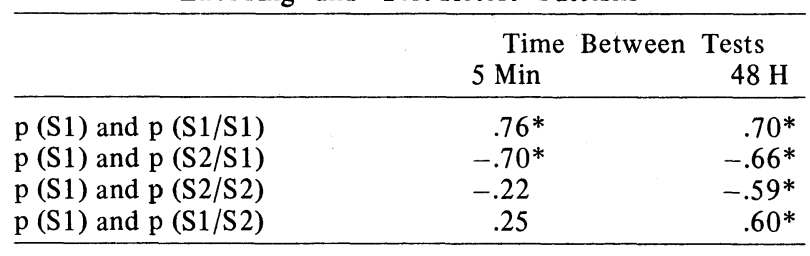

${ }^{*} p<.01$

pooled observations across Ss and conditions. Data from the 5-min and 48-h conditions were combined, since analyses of variance, as earlier reported (Winograd \& Geis, 1974), indicated no effect of intertest interval on the encoding patterns listed in Table 1.

In the first column, $\mathrm{p}$ (same) is the likelihood of making the same semantic encoding at test and retest, i.e., the likelihood of sticking to the same semantic encoding over time. In the second column, the likelihood of a switch to $\mathrm{S} 1$ at retest is conditionalized on the occurrence of $S 2$ at the first test, $\mathrm{p}(\mathrm{S} 1 / \mathrm{S} 2)$. In the last column, the probability of a switch to $S 2$ is conditionalized on the prior occurrence of $\mathrm{S} 1, \mathrm{p}(\mathrm{S} 2 / \mathrm{S} 1)$.

We note that, in general, encoding stability is the rule, and, when a change occurs, the switch is more likely to be from $\mathrm{S} 2$ to $\mathrm{S} 1$ than from $\mathrm{S} 1$ to $\mathrm{S} 2$. Statistical support for this observation is provided in the earlier paper. One description of this pattern of results is that a "pull" is exerted by $\mathrm{S} 1$ and that the force of this pull is proportional to the strength or normative encoding probability of S1. To test this hypothesis further, correlations were computed between $\mathrm{p}(\mathrm{S} 1)$ and various test-retest conditional probabilities across the 50 homographs. As shown in Table 2, there was a substantial and significant positive correlation between the normative encoding probability of the primary semantic sense and the probability of repeating that encoding at $5 \mathrm{~min}$ or $48 \mathrm{~h}$. There was also a substantial and significant negative correlation between the strength of S1 and the likelihood of a switch from S1 to S2. When the secondary encoding was made at first test, a drift to the primary encoding at retest occurred as the strength of the primary encoding increased. The difference between the $\mathrm{p}(\mathrm{S} 2 / \mathrm{S} 2)$ correlations at $5 \mathrm{~min}$ and $48 \mathrm{~h}$ (third row in Table 2) was significant, $\mathrm{z}=2.13$, $\mathrm{p}<.05$, as was the difference between the $\mathrm{p}(\mathrm{S} 1 / \mathrm{S} 2)$ correlations, $z=2.06, p<.05$. Thus, when the time between successive encodings was extended, the likelihood of sticking to S2 decreased and the likelihood of switching to S1 increased, as the strength of S1 increased.

Our data showing the importance of the strength of the primary encoding are in good agreement with the data of Fox (1970). Fox administered identical word association tests with a test-retest interval of 59 days and scored the responses by exact words rather than by semantic senses. His reported correlation of .74 between the normative strength of the primary word associate and the probability of its repetition is consistent with the values in the top row of Table 2. Our data and Fox's are also similar with respect to the likelihood of repetition of the exact word at both tests. Fox found that the probability of within-S word change was .52 , while for our data, the over-all probability of a word change was .48 . For further discussion of these data as well as other data, the reader is referred to Winograd and Geis (1974).

\section{REFERENCES}

Cramer, P. A study of homographs. In L. Postman and G. Keppel (Eds.), Norms of word association. New York: Academic Press, 1970.

Fox, P. W. Patterns of stability and change in behaviors of free association. Journal of Verbal Learning \& Verbal Behavior, 1970, 9, 30-36.

Kausler, D. H., \& Kollasch, S. F. Word associations to homographs. Journal of Verbal Learning \& Verbal Behavior, $1970,9,444-449$.

Light, L. L., \& Carter-Sobell, L. Effects of changed semantic context on recognition memory. Journal of Verbal Learning \& Verbal Behavior, 1970, 9, 1-11.

Martin, E. Stimulus meaningfulness and paired-associate transfer: An encoding variability hypothesis. Psychological Review, $1968,75,421-441$.

Perfetti, C. A., Lindsey, R., \& Garson, B. Association and uncertainty: Norms of association to ambiguous words. University of Pittsburgh, 1971.

Rowe, E. J. Frequency judgments and recognition of homonyms. Journal of Verbal Learning \& Verbal Behavior, 1973, 12, 440-447.

Winograd, E., \& Conn, C. P. Evidence from recognition memory for specific encoding of unmodified homographs. Journal of Verbal Learning \& Verbal Behavior, 1971, 10, 702-706.

Winograd, E., \& Geis, M. F. Semantic encoding and recognition memory: A test of encoding variability theory. Journal of Experimental Psy chology, in press.

(Received for publication April 5, 1974.) 